\title{
The Syntax and Morphology of the Negative Morphemes /sa/ in Sesotho
}

\author{
Elias Nyefolo Malete *
}

\begin{abstract}
Sesotho is one of the African Languages where sentence negation is expressed by means of bound negative morphemes. It has only three negative morphemes which are spread across the Sesotho matrix and subordinate clauses. They are the negative morphemes /ha/, /sa/ and /se/.These morphemes are bound verbal morphemes that negate various predicate forms and only appear in restricted sentence types. The central aim of this paper is to examine sentence constructions that realize negation by means of the negative morpheme /sa/ and its syntactic distribution within copulative verbs, non - copulative verbs, deficient verbs and aspect morphemes over a full range of inflectional categories such as tense, aspect and mood. This morpheme will be examined within the general framework of the Minimalist Programme, which holds that inflectional categories occur as heads of phrasal categories. This paper will further illustrate the morphological representations of these morphemes within Beard's (1995) Lexeme-Morpheme Base Morphology, which defines morphology as the sum of all the phonological means of expressing the relations of constituents in words, of words in phrases and of phrasal constituents in sentences. It distinguishes lexemes from bound morphemes.
\end{abstract}

Key words: syntax, morphology, negative, Sesotho

\section{Introduction}

In African languages, negation as a grammatical phenomenon has not been widely investigated within the Generative Approaches. It has been dealt with in relation to positive sentences, where it is usually indicated that negative sentences correspond to positive sentences.

Within the structural approach, Doke and Mofokeng (1985: 196) recognized the negative prefix /sa/ as a negative form that corresponds to definite and indefinite present positive tenses and appears in all tenses of the participial mood. They distinguished negative conjugation of Sesotho into six types, of which two have the negative prefix /sa/ as a

\footnotetext{
* Elias Nyefolo Malete: Department of African Languages, University of the Free State - Qwaqwa Campus, Private Bag X 13, Phuthaditjhaba, 9866, South Africa. E-mail: maleteen@ qwa.uovs.ac.za.
} 


\section{Elias Nyefolo Malete}

negative marker. Guma (1971:166) identified the negative morpheme /sa/ as a conjugational morpheme, an indicative participial negative prefix that appears in the present, perfect and future tenses.

Negation according to Zanuttini (1997) is a syntactic process whereby a language employs negative markers to negate a clause. She categorizes negative markers into pre-verbal negative markers and post-verbal negative markers. Pre-verbal negative markers that can negate a clause on their own head a negative phrase. They have strong features which need to be checked, and structurally they precede all the clitics. Klima (1964) stipulates that sentence negation is realized when negative pre-verbal particles are present in the sentence. Haegeman's (1995) analysis of sentence negation is based on Negative-Criterion, the well-formedness condition that determines the distribution and interpretation of the negative element. It requires the spec-head relation between the negative operator and the negative head in terms of the X-bar scheme. In his comparative analysis of the negative, Guldemann (1999: 545-587) maintains that Bantu Languages express negation by way of periphrastic construction, by giving a distinction between bound and unbound negative markers and by ordering morphemes into pre-initial affixes or post-initial affixes. He goes on to say that with pre-initial negation, the predicate can be analyzed as a binary structure wherein a negative nucleus bears the illocutionary force and a finite satellite conveys the prepositional information of the predicate.

This paper will examine the distribution and morphology of the negative morpheme /sa/ within non-copulative verbs, copulative verbs, deficient verbs and aspect morphemes. It will also be demonstrated that the negative morpheme /sa/ is a bound verbal morpheme, a functional category that heads the negative phrase.

\section{Theoretical background}

The morphology of the negative morpheme/sa/ is examined within the LexemeMorpheme base Morphology of Beard (1995), which distinguishes lexemes from bound grammatical morphemes. Lexemes are signs which appear in open classes as direct specified sequence of phonemes with grammatical and semantic intensions. They are the only minimal grammatical elements in the language and each lexeme has a set of three representations, viz. phonological, grammatical and semantic representations. Morphemes, according to Blake and Moorhead (1993: 5), are the smallest units of language that have independent meaning. Beard (1995) distinguishes between bound grammatical morphemes, which are morphological spelling operations that mark modifications in inflectional 
categories, and free morphemes which mark closed grammatical categories such as articles, prepositions and pronouns.

In terms of bound morphology, derivation on lexemes is referred to as lexical derivation, where morphological spelling operations change the categorical status of lexemes. In Sesotho for instance, the verb [sebets-] will change its verbal status to that of nominal status as [mo-sebets-i]. On the other hand, derivation on morphemes is referred to as inflectional derivation, where morphological spelling operations do not change the categorical status of lexemes. Inflectional derivation is further divided into nominal inflectional derivation and verbal inflectional derivation. Nominal inflectional derivation is concerned with nominal categories such as case, gender and number, while verbal inflectional derivation is concerned with grammatical features such as tense, mood, agreement, aspect and negative. In Sesotho, if the verb /ken/ is inflected by categories with features such as [present], [participial], [singular] and [negative], the phonological spelling of the lexeme $/ \mathrm{ken} /$ reads as illustrated the sentence in (1) and the diagram (1) below:

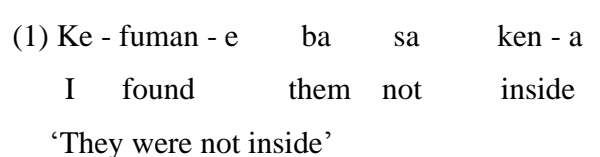

\section{Diagram 1: Morphological structure of the negative [sa]}

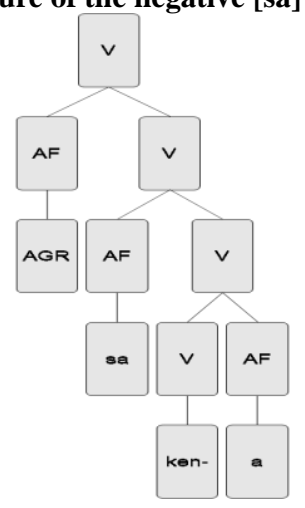

According to the structure in (1) above, the negative morpheme /sa/ is a bound morpheme that is inflected to the lexeme $/ \mathrm{ken} /$. It precedes the verb and therefore a pre-verbal negative morpheme. According to Haegeman (1995), bound morphemes have strong morphological features and, following Zanuttini's (1997) view, pre-verbal negative markers should head negative phrases.

The syntax of the negative morpheme /sa/ will be examined within the Minimalist Programme. It maintains that the properties and distribution of clauses are determined by 


\section{Elias Nyefolo Malete}

the nature of verb inflection. Inflectional features are separated and turned into fully phrasal categories, with their morphemes becoming heads of such phrases. Tense, mood, agreement, aspect and negative will be turned into TP, MP, AGRSP, AGROP, ASPP and NEGP. According to Thrainsson et al. (1996), the order and nature of these inflectional categories is determined by the Mirror Principle, which stipulates that morphemes furthest from the verb occupy higher structural positions in the functional layer of the clause. Haegeman (1997), states that strong morphological features of functional categories are phonologically visible, and bound morphemes have strong features that will cause the verb to move and check its inflected features. Negative sentences are therefore constructions, which minimally have negative features associated with a functional head of the extended projection of the verb. This implies that the negative elements are identified as negative phrases headed by a negative head, where the head is in geometrical position with its specifier. Zanuttini (1997) also maintains that pre-verbal negative markers have strong features and head a negative phrase. Following Haegeman's (1997) and Zanuttini's (1997) views, the negative morpheme /sa/ in Sesotho will head a negative phrase as illustrated in diagram (2) below:

Diagram 2: NegP with the negative morpheme [sa] as head

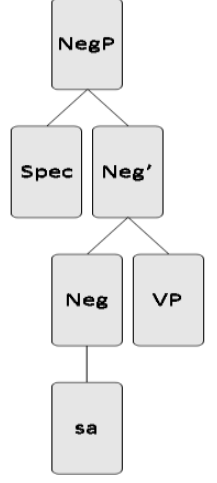

Having discussed the theoretical background, this paper shall now look into the morphology and distribution of the negative morpheme /sa/.

\section{The syntax and morphology of the negative morpheme /sa/}

The second negative morpheme in Sesotho is the negative [sa]. It occupies the third position in the linear order of the verbal prefixes of Sesotho. The negative morpheme [sa] only appears in the participle and the relative moods. Its distribution will therefore be investigated within these two moods and predicate forms such as non-copulative verbs, 
copulative verbs and deficient verbs, as well as aspect morphemes. Further more, the negative morpheme [sa] as a bound morpheme, appears as a circumfix with the negative suffixes such as [-e] and [-a] as determined by the types of tenses it appears with. Its morphology will therefore be treated simultaneously with its syntactic distribution through diagrammatic representations.

\subsection{The negative morpheme /sa/ in non-copulative verbs}

Non-copulative predicates are verbs that denote actions done by the subjects or individuals. Van Valin and La Polla (1997: 91) classify verbs and other predicating elements in terms of their inherent temporal properties: They are stative verbs [sick, talk, love, know], achievement verbs [explode, collapse], accomplishment verbs [freeze, melt, learn] and activity verbs [march, walk, roll]. Malete (1996: 49), gives a classification of verbs according to the type of actions verbs denote: Experiencer verbs [rata/ love; hloya/ hate]; sensory verbs [utlwa/ hear; bona/ see]; verb [lema /plough; kganna/ drive],rejecting and accepting verbs [hana/ refuse; amohela/ accept], asking and answering verbs [botsa/ask; araba/answer] and verbs of advice [eletsa; lemosa: advise/aware].

Du Plessis and Visser (1992: 1) classify verbs according to the number of arguments upon which a predicate operates. They are described as one-place predicates (intransitive), two-place predicates (transitive) and three-place predicates (ditransitive). It is the last type of verbs which is going to be considered in this paper, especially with reference to subordinate clauses.

In this case, the negative morpheme [sa] appears in the participial mood within three tenses, namely the present, perfect and future tenses. In the present tense, the negative morpheme [sa] appears with the negative suffix [-e] as shown in (2) and diagram (3) below:

Diagram 3: Morphological structure of negative morpheme [sa] in the Present tense

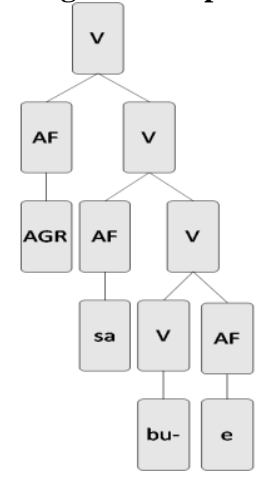




\section{Elias Nyefolo Malete}

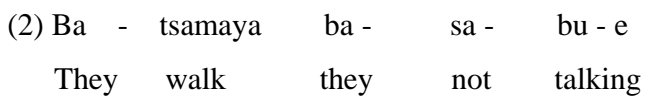

'They walk while not talking'

In the perfect tense, the negative morpheme [sa] appears with the suffix [-a] and the perfect negative morpheme [-a] does not appear. The sentence in (3) with the morphological structure of the participial complement in diagram (4) illustrate the above observation:
(3) Ba tsama - ile ba -
sa - bu - a
They walk - ed they
not talk - ed
'They left without a word'

Diagram 4: Morphological structure of the negative morpheme [sa] in the perfect tense

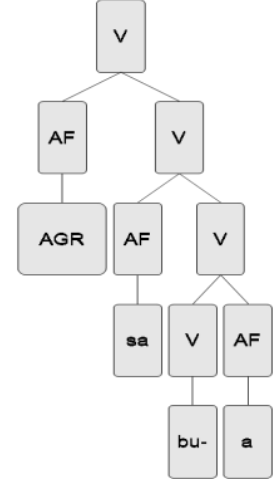

In the future tense, the negative morpheme [sa] still appears with the suffix [-a] and the future tense morpheme [tla] in the complement clause. The future tense morpheme [tla] of the present tense coalesces with the infinitive to form [tlo] as illustrated in (4a). The motion verb [ya] may also coalesce with the infinitive to form [yo] and appear with the negative [sa] where it replaces [tlo] as shown in (4b). The morphological structure of (4a-4b) will be the same as illustrated in diagram (5) below:

Diagram 5. The morphological structure of the negative morpheme [sa] in the Future tense

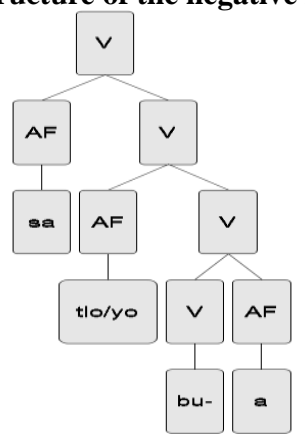


The Syntax and Morphology of the Negative Morphemes /sa/ in Sesotho

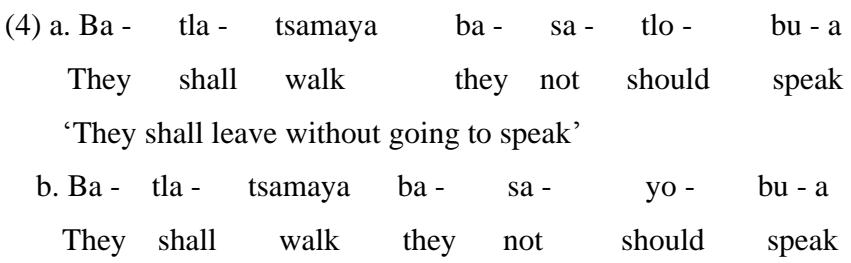

'They shall leave without going to speak'

It is observed from the above sentences that the negative morpheme [sa] appears with different morphemes in the participial mood depending on various tenses. In the present tense the verb employs the negative suffix [-e], in the perfect tense the verb retains the suffix [-a], and in the future tense the verbs employ the future tense morpheme [tla].

The negative morpheme [sa] may also appear in the relative mood with three tenses, namely the present, future and perfect tenses. It should be noted that the relative in Sesotho appears in two different forms. In the first case, when the antecedent of the relative clause is also the subject of the relative clause, the subjectival agreement [AGRS] in the relative clause coalesces with the complementizer of the relative clause. The sentence in (5.a) becomes the sentence in (5b), as the arrow indicates. See the illustration in (5) below:

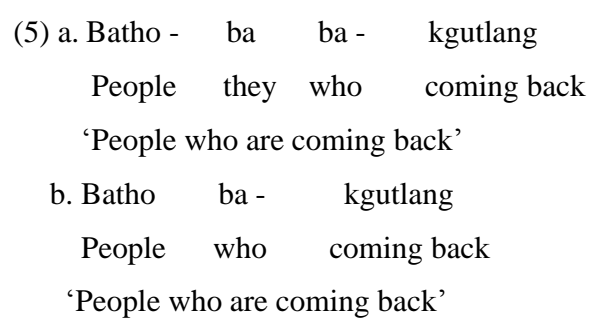

In this case as in (5b) above, an empty [pro] coindexed with the antecedent and the complementizer appears as illustrated in (6) below:

(6) Batho $_{\mathrm{i}} \quad \mathrm{ba}_{\mathrm{i}} \quad \mathrm{pro}_{\mathrm{i}}$ - $_{\text {kgutlang }}$

People who pro coming back

'People who are coming back'

In the second case, the subject of the relative clause is not the antecedent and the subjectival agreement is retained as indicated in (7) below:

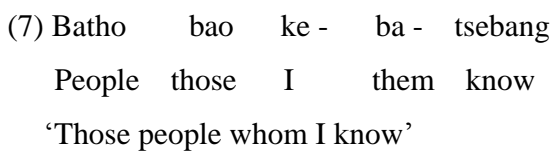

The morphological structure of the sentence in (7) above will be as in diagram (6) below: 


\section{Elias Nyefolo Malete}

\section{Diagram 6: Morphological structure of the verbal relative clause}

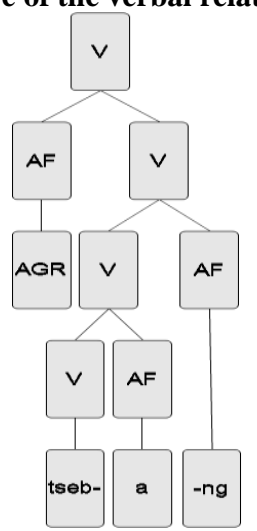

The relative sentences such as those in (6) and (7) are negated by the negative morpheme [sa]. In the present tense, the negative morpheme [sa] will appear with the negative suffix [-e] and the relative marker [-ng]:
(8) a. Batho ba - sa- kgutl - e - ng
People they not coming back
b. Batho bao ke-sa- ba- tseb-e-ng
'People who don't come back'
People those I not them know
'People whom I don't know'

The morphological structures of the sentences in (8) will be as in diagram (7) below, indicating the negative morphemes [sa] and [-e-] as well as the relative suffix [-ng]:

Diagram 7: Morphological structure of negative [sa] in the relative mood

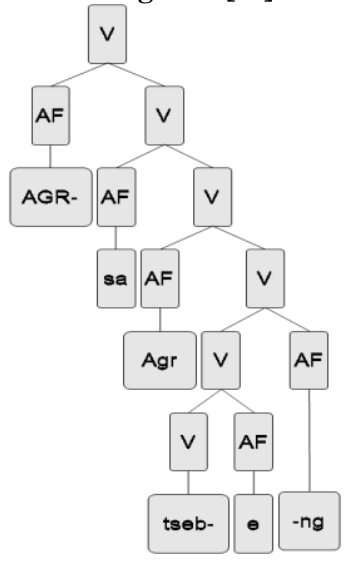

In the case of the perfect tense, the negative morpheme [sa] will appear with the suffix [-a-] together with the relative marker [-ng]. The perfect negative affix [-a-] does not appear with the negative [sa]. This is illustrated by the sentence in (9) with its morphological structure in diagram (8): 
The Syntax and Morphology of the Negative Morphemes /sa/ in Sesotho

(9) Batho bao ke - sa - ba - tseb-a - ng
People those I not them knew
'People whom I didn't know'

Diagram 8: Morphological structure of negative [sa] in the perfect tense

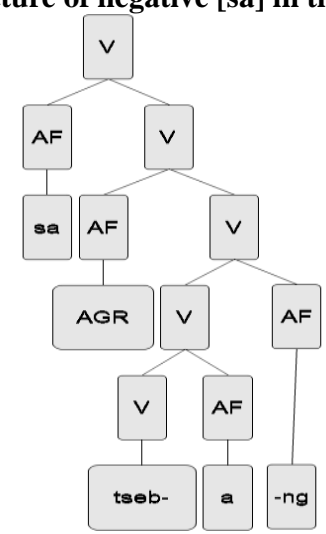

In the future tense, the negative morpheme [sa] will appear with the future tense morpheme [tlo], the verb will retain its suffix [-a-] and have the relative marker [-ng]. The future tense morpheme [tlo] is the coalesced form of the present tense and the infinitive. The motion verb [ya] will also appear with the negative [sa] in a coalesced form as [yo]. The sentences in (10) will illustrate:

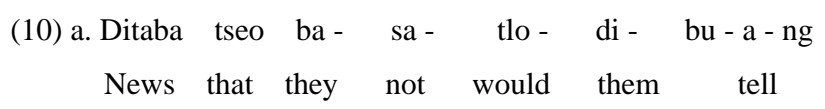

'The news that they will not tell'

b. Ditaba tseo ba - sa- yo- di - bu-a-ng
News that they not would them tell

'The news that they are not going to tell'

From the above observations, it is clear that the negative morpheme [sa] in the relative mood appears with different morphemes depending on different tenses. In the present tense, it appears with the negative suffix [e], in the perfect tense the perfect negative prefix disappears while the verb retains the suffix [-a-]. In the future tense it appears with the future tense morpheme [tlo].

\subsection{The negative morpheme /sa/ with copulative verbs}

As described by Du Plessis and Visser (1995: 217), copulative verbs take special or exclusive complements, such as the adjectives, nominal relatives, comparative elements and quantifiers. There are six copulative verbs that are recognized in Sesotho. They are the copulatives [le], [ke], [li], [na], [se] and [ba]. However, the copulatives [le]; [ke]; [se]; and 


\section{Elias Nyefolo Malete}

[ba], may also appear with other complements, which are not exclusive to copulatives as illustrated by the sentences below:

Noun Phrase as complement

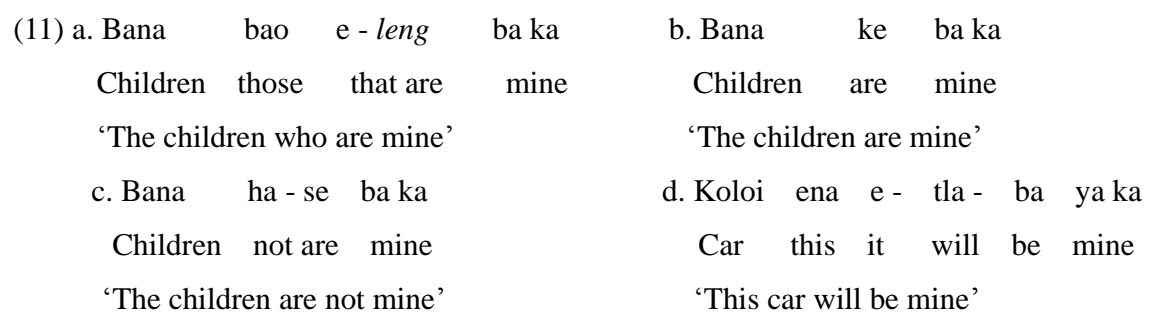

\section{NP Locatives as complements with reference of time}
(12) a. E-ne e-le nakong eo dikgomo di- fihlang ho-tswa naheng It was it is at the time which cattle were arriving to from veld 'It was at the time when the cattle were arriving from the veld'
b. Ke nakong eo dikgomo di - fihlang ho - tswa naheng
It is at the time which cattle were arriving to from veld

'It is the time at which the cattle arrived from the veld'
c. Ha - se nakong eo dikgomo di - fihlang ho tswa naheng
Not it is at the time which cattle were arriving to from veld
'It is not the time at which the cattle were arriving from the veld'
d. E - tla - ba nakong eo dikgomo di fihlang ho tswa naheng It will be at the time which cattle were arriving to from veld
'It will be the time at which the cattle were arriving from the veld'

\section{The Infinitive as complements}

(13) a. Taba e - le ho - pheisana kgang
The point it be to debate argument
'The point being to argue'
b. Taba ke ho - pheisana kgang
The point is to debate argument
'The point is to argue'
c. Taba ha - se ho - p heisana kgang
The point not is to argument
'The point is not to argue' debate pheisana kgang
d. Taba ya - eba ho - pargument
The point came to be to debate are a


The Syntax and Morphology of the Negative Morphemes /sa/ in Sesotho

'The point then became to argue'

The hore-clause as complement

(14) a. Kgopolo ya hae e - ne e-le hore o- $\quad$ se- a- qetile Idea of him/her it was it be that he/she is now finished

'His/her idea was that he has already finished'

b. Kgopolo ya hae ke hore o-qetile

Idea of his/her is that he/she is finished

'His/her idea is that he/she has finished'

c. Kgopolo ya hae ha-se hore o- se - a - qetile

Idea of his/hers not is that he/she is now finished

'His/her idea is not that he/she has already finished'

d. Kgopolo ya hae ya - eba hore o - se - a - qetile

Idea of his/hers came to be that he/she is now finished

'His/her idea was that he/she has already finished'

\section{Prepositional Phrase as complement with [ka] as head}

$\begin{array}{rllllll}\text { (15) a. E - ne } & \text { e - le } & \text { ka madungwadungwane } & \text { ka tsatsi la } & \text { Moqebelo } \\ \text { It was } & \text { it is } & \text { at } & \text { dawn } & \text { by the day of } & \text { Saturday }\end{array}$

'It was by early dawn of Saturday'

b. Ke ka madungwadungwane ka tsatsi la Moqebelo

It is at dawn by the day of Saturday

'It is at early dawn of Saturday'

c. Ha - se ka madungwadungwane ka tsatsi la Moqebelo

Not is at dawn by the day of Saturday

'It is not at early dawn of Saturday'

d. E - tla - ba ka madungwadungwane ka tsatsi la Moqebelo

It will be at dawn by the day of Saturday

'It will be at early dawn of Saturday'

However, the negative morpheme [sa] appears only with the copulative verb [ba] in both the relative and participial moods with all tenses. In the relative mood of the present tense, the negative morpheme [sa] appears with the negative suffix [-e] and the relative marker [-ng]. This is illustrated in (16) below:

$$
\begin{aligned}
& \text { (16) a. Motho ya- sa- b-e-ng le bana } \\
& \text { A person who not having with children }
\end{aligned}
$$

'A person who does not have children' 


\section{Elias Nyefolo Malete}

$\begin{array}{rrrrrrr}\text { b. Batho } & \text { bao } & \text { a }- & \text { sa }- & \text { b-e -ng } & \text { le bona ka mehla } \\ \text { People who he/she } & \text { not } & \text { being } & \text { with them at all times }\end{array}$

'People whom he/she is not with them always'

The morphological structure of the negative predicates in (16) will be the same as in diagram (9) below:

Diagram 9: Negative morpheme [sa] in the relative mood of the present tense with copulative [ba]

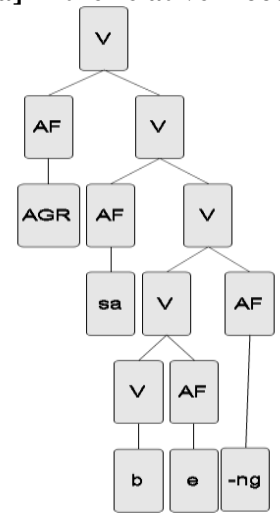

In the perfect tense, the negative morpheme [sa] will appear with the relative marker [-ng], but retain the suffix [-a] as demonstrated by the sentences in (17) below:
(17) a. Motho ya- sa-
b-a-ng le bana
A person who not
had with children

'A person who did not have children'
b. Batho bao a - sa- b-a-ng le bona
People those he/she not be with them

'People whom he/she was not with'

The above sentences in (17) will have the morphological structure in (10) below:

Diagram 10: Negative morpheme [sa] in the relative mood of the prefect tense with the copulative [ba]

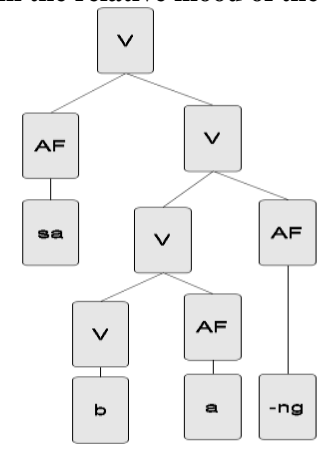

In the future tense, the negative morpheme [sa] will appear with the future tense 
morpheme [tlo] and the deficient motion verb [yo], which is the coalesced forms of the present tense [tla] and the verb [ya] with the infinitive. The sentences in (18) and (19) with their morphological structure in diagram (11) will illustrate:

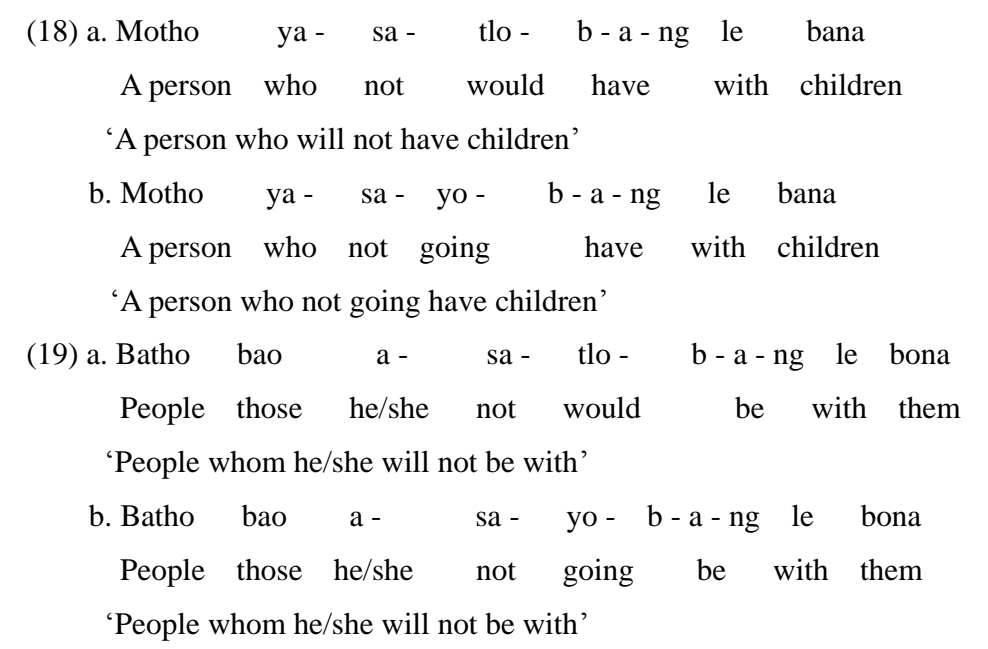

Diagram 11: Negative morpheme [sa] in the relative mood of the future tense with copulative [ba]

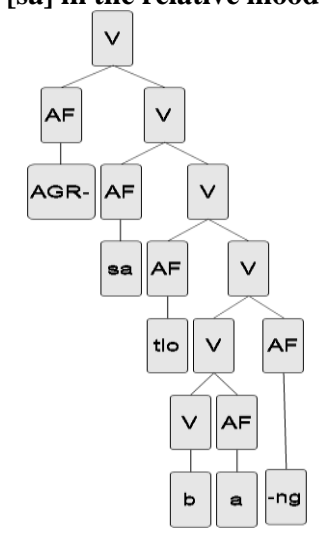

From the above sentences, it is clear that in the relative mood, the negative morpheme [sa] appears with the suffix [-e] in the present tense, with the suffix [-a] and the relative marker in the perfect tense, and with the future tense morpheme [tlo], in the future tense. The negative morpheme [sa] may also appear with the copulative verb [ba] in the participial mood with all the three tenses, namely: present, perfect and future tenses. In the present tense, the negative morpheme [sa] appears with the negative suffix [-e] as shown in (20) below:

$\begin{array}{ccccccc}\text { (20) } \mathrm{O}- & \text { dula } & \mathrm{a}- & \mathrm{sa}- & \mathrm{b}-\mathrm{e} & \text { le } & \text { tjhelete } \\ \mathrm{He} / \mathrm{she} & \text { stays } & \text { he/she } & \text { not having } & \text { with } & \text { money }\end{array}$ 


\section{Elias Nyefolo Malete}

'He/she stays without having money'

The morphological structure of the above sentence in (20) will be as in diagram (12) below:

Diagram 12: Negative morpheme [sa] in the participial mood of the present tense with copulative [ba]

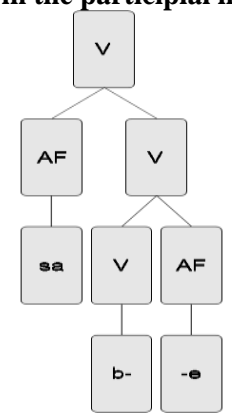

In the perfect tense, the negative morpheme [sa] appears with the suffix [-a], the negative perfect morpheme [-a-] disappears as the sentence in (21) with its morphological structure in diagram (13) will illustrate:

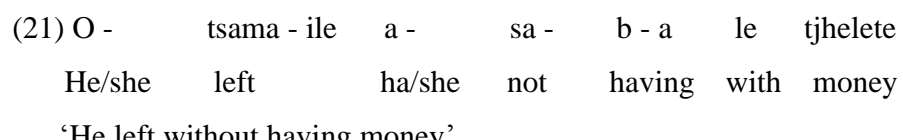

Diagram 13: Negative morpheme [sa] in the participial mood if the perfect tense with copulative [ba]

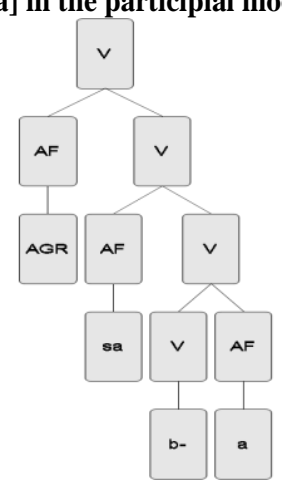

In the future tense, the negative morpheme [sa] appears with the future tense morpheme [tlo] and the motion verb [yo] in the complement of the participial clause. The morpheme [tlo] and the verb [yo] are the coalesced forms of the present tense [tla] and the verb [ya] and the infinitive. The sentences in (22) with the morphological structure of the participial complement in diagram (14) illustrate:

$\begin{array}{rllllll}\text { (22) a. O - } & \text { tla - } & \text { tsamaya } & \text { a - } & \text { sa }- & \text { tlo - } & \text { b-a le tjhelete } \\ \mathrm{He} / \mathrm{she} & \text { will leave } & \text { he/she } & \text { not would have with money }\end{array}$


The Syntax and Morphology of the Negative Morphemes /sa/ in Sesotho

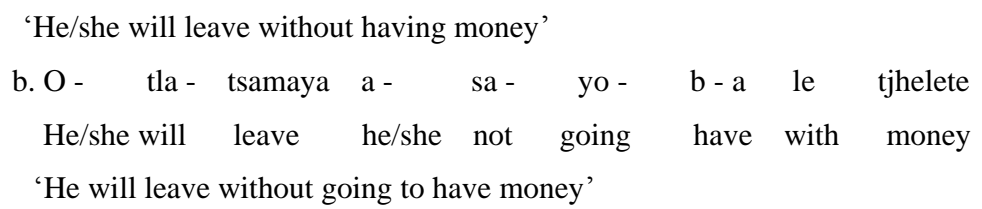

Diagram 14: Negative morpheme [sa] in the participial mood of the future tense with copulative [ba]

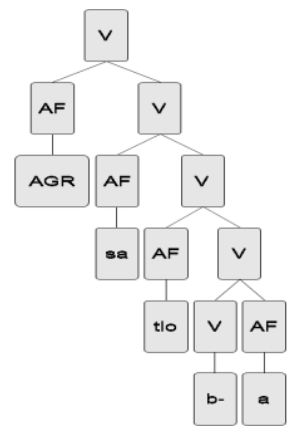

From the above observation, it is clear that the negative morpheme [sa] also appears with the negative suffix [-e] in the present tense. In the perfect tense, it appears with the suffix [-a] where the perfect negative morpheme [-a-] does not appear. In the future tense the negative [sa] appears with the coalesced [tlo].

\subsection{The neagative morpheme /sa/ with deficient verbs}

According to Guma (1971: 187), deficient verbs are verbs that cannot be used by themselves to have a complete verbal predicate, but need another verbal complement for a complete meaning. He distinguishes two types of deficient verbs, namely permanent deficient verbs and non-deficient verbs which are deficiently used. He further divides deficient verbs into influencing and non-influencing verbs. There are however some deficient verbs which may play a specific role in negative sentences:

In this case the negative morpheme [sa] only appears with the deficient verb [ka] in the compound tense of the consecutive mood and the negative of the potential mood. The negative morpheme [sa] does not appear with the deficient verb [-eso] as in the case of the negative morpheme [ha].

\subsubsection{The negative of the compound tense with [-ile]}

The deficient verb [-ile] appears with the consecutive clause to form a compound tense as illustrated by the sentence in (23) below:
(23) Leha ke-ile ka - baleha
Even if I did could run away
'Even if I did run away' 


\section{Elias Nyefolo Malete}

In the negative of the compound tense, the deficient verb [-ile] disappears. The negative of the clause in (24) will be formed by the negative morpheme [sa] and the deficient verb [ka]. The negative prefix [-a] of the perfect tense does not appear. The negative sentence of the above sentence in (23) will be as in (24) with its morphological structure illustrated in diagram (15):

\begin{tabular}{|c|c|c|c|}
\hline (24) Leha & ke - sa - ka & $\mathrm{ka}-$ & baleha \\
\hline Even if & I not could & could & ran away \\
\hline
\end{tabular}

\section{Diagram 15: Negative morpheme [sa] in the compound tense with the deficient verb [ka]}

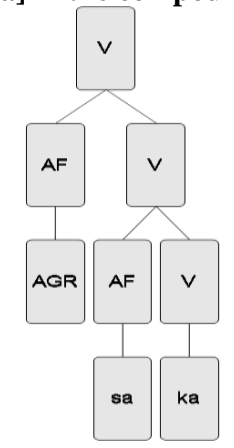

2.3.2. The negative of the potential mood

The sentence constructions in potential mood are recognized by the potential morpheme [ka], which appears before the verb stems as shown in (25) below:

$$
\begin{aligned}
& \text { (25) Leha re - ka baleha } \\
& \text { Even if we can run away } \\
& \text { 'Even if we can run away' }
\end{aligned}
$$

The negative of the potential mood has various forms. There is however no negative construction of the potential mood with the negative morpheme [sa]. The only negative construction with the potential mood with the exception of the negative morpheme [se] is with the deficient verb [ka], where the potential morpheme [ka] is changed to [ke] and the suffix of the deficient verb [ka] is also changed into the negative suffix [-e] to form [k-e]. The sentence in (26) with the morphological structure in diagram (16) illustrates:

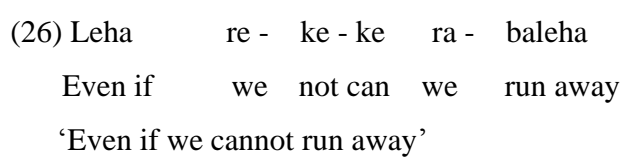

Diagram 16: Negative morpheme [sa] in the potential mood with the deficient verb [ka] 


\subsubsection{The deficient verb [-eso-]}

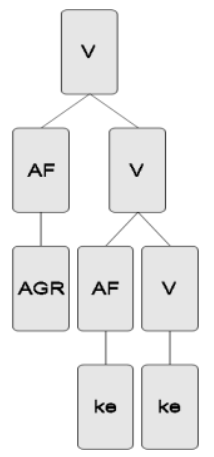

The verb [-eso-] is an inherent negative verb. It may appear in the participial mood where its complement verb has the suffix [-e]. The sentence in (27) illustrates:

$$
\begin{aligned}
& \text { (27) a. Leha ba - eso - baleh - e } \\
& \text { Even if they not yet ran away } \\
& \text { 'Even if they haven't yet ran away' } \\
& \text { b. Leha ba - eso ho - baleh - e } \\
& \text { Even if they not yet to run away }
\end{aligned}
$$

'Even if they haven't yet ran away'

As observed from the sentences in (27) above, there is no negative morpheme that appears with the deficient verb [-eso-]. The negative morpheme [sa] also, cannot appear with the deficient verb [-eso-]. It would seem this deficient verb only appears as the negative verb with the negative morpheme [ha]. Where there is no negative morpheme as in (27) above, the verb [-eso-] becomes the negative morpheme as illustrated by the structure in diagram (17) below:

Diagram 17: The negative morpheme [eso] in the participial mood

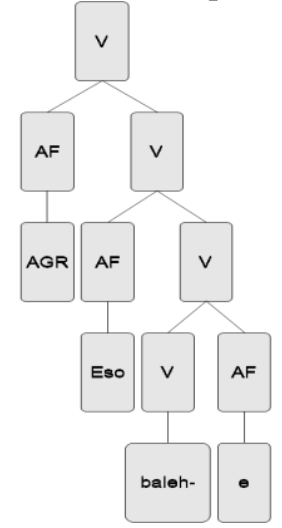




\section{Elias Nyefolo Malete}

From the above observation, it is clear that the negative morpheme [sa] has a very limited appearance with deficient verbs. In the negative of the potential mood, the negative morpheme [sa] is replaced by the deficient verb [ka] and it does not appear at all with the deficient verb [-eso]. In other words, the negative morpheme /sa/ and the deficient verb /eso/ are complementary to each other, where the negative morpheme [sa] is not used, the deficient verb [eso] serves as the negative morpheme. It appears mainly with the compound tense with [ile].

\subsection{The negative morpheme /sa/ with aspect morphemes}

The notion aspect according to Canonici (1995: 67), quoted by Sithole (2003: 202), refers to the duration and type of action being described, it relates to internal time of the situation, divided into perfective and imperfective, and is expressed by some morphemes on the verbs or by a special periphrastic verb constructions.

The aspectual morphemes identified in Sesotho are the progressive aspect morpheme [sa], the necessity aspect morpheme [-no-], the consecutive aspect morpheme [-nto-] and the temporal aspect morpheme [tswa]. Chapole (1992: 54) further identifies Sesotho aspectual morphemes as durative marker [-a] of the long form present tense; persistive aspectual marker [-ntse] and the habitual aspect markers such as [ye]; [hle]; [nne] and [be].

In the case of aspect morphemes, the negative morpheme [sa] may not appear with the progressive aspect morpheme [sa] in both the participial and the relative moods, because their negative morpheme is also [sa]. The progressive morpheme [sa] can appear with the temporal aspect morpheme [tswa], but there is no negative in such constructions with the negative morpheme [sa].

The negative morpheme [sa] may be forced to appear with the progressive morpheme [sa] in the participial mood as indicated in (28) below:

(28) ${ }^{*} \mathrm{O}-$
$\mathrm{He} / \mathrm{she}$ found $\mathrm{him} / \mathrm{her}$ still not eating
'He/she found him/her no longer eating'

The sentence in (28) above is problematic in that the negative morpheme of this mood is also [sa]. It is therefore not a readily acceptable construction. To force an acceptable negative, the deficient verb [se] is used and is followed by the negative complement with [sa] and the negative suffix [-e], as indicated by (29) and in diagram (18) below:

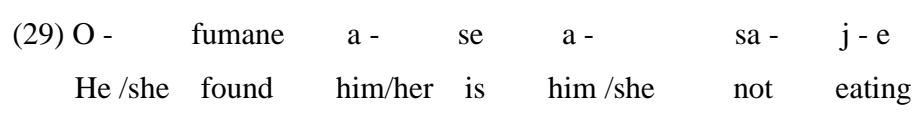

'He found that he/ she was no longer eating' 
The Syntax and Morphology of the Negative Morphemes /sa/ in Sesotho

\section{Diagram 18: Negative morpheme [sa] in the participial mood}

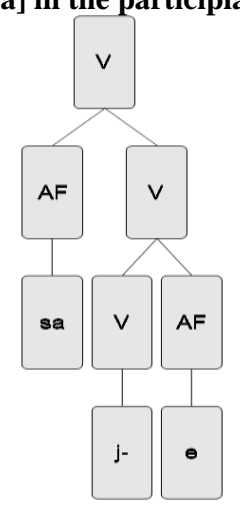

The negative morpheme [sa] may also be forced to appear with the aspect morpheme [sa] in the relative mood as shown in (30) below:

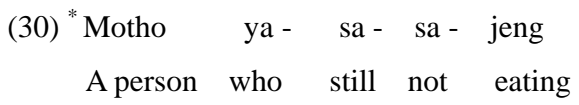

'A person who no longer eats'

As in the case of the participial mood, the sentence in (30) is also not readily acceptable. To force the negative, the deficient verb [se] will appear with the relative marker [-ng] and be followed by the negative complement with the negative morphemes [se] and suffix [-e], as illustrated by (31) and in diagram (19) below:

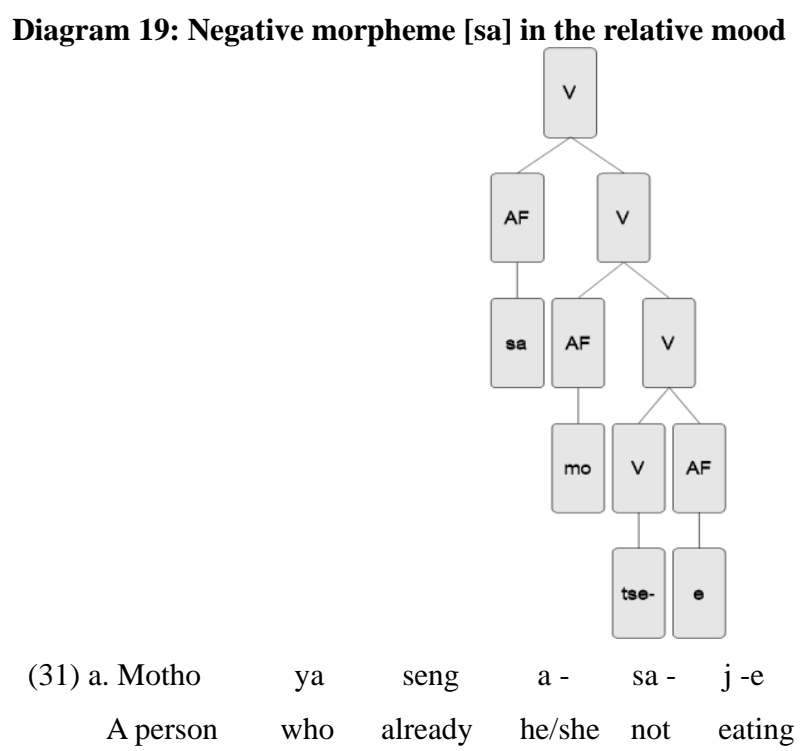

'A person who is already not eating' 


\section{Elias Nyefolo Malete}

$$
\begin{aligned}
& \text { b. Motho eo ke seng ke - sa - mo - tseb-e } \\
& \text { A person who I already I not him/her know }
\end{aligned}
$$

The morphological structure for the negative complement in (31a) will be the same as the structure in (19) above. The deficient verb [se] may also be used to help in negating the copulative verb [ba], where the negative morpheme [sa] appears with the negative suffix [-e]:

(32) Tjhelete e- se e - sa - b-e ngata
Money it could it not be much any longer

'Money was no longer enough'

The morphological structure of the negative complement in (32) will be as in diagram (20) below:

\section{Diagram 20: Negative morpheme [sa] in the participial mood}

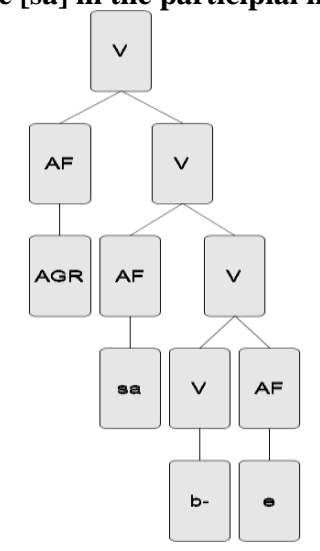

The aspect morphemes [sa] and [tswa] can appear together in the participial mood and the relative mood in the positive as indicated in (33) below:

$\begin{array}{ccccc}\text { (33) a. A- } & \text { fihla } & \text { ba- sa- } & \text { tswa- bua } \\ \text { He/she } & \text { arrived they still have spoken }\end{array}$

'He arrived after they have spoken'

$\begin{array}{ccclllll}\text { b. Motho } & \text { eo } & \text { ke- } & \text { fumaneng } & \text { a - } & \text { sa - } & \text { tswa- } & \text { bua } \\ \text { A person } & \text { whom } & \text { I } & \text { found } & \text { he/she } & \text { still } & \text { have } & \text { spoken }\end{array}$

'A person whom I found after he/she has spoken'

It is however not possible to have a negative construction with the negative morpheme [sa] in the above sentences.

From the above observation, it is clear that when the negative morpheme [sa] has to 
appear with the aspect morpheme [sa], the latter is dropped to be replaced by the deficient verb [se], so that the negative [sa] becomes the complement of [se]. The negative morpheme [sa] cannot appear with the temporal morpheme [tswa], but the progressive [sa] can only appear with [tswa] in the positive.

\section{Summary and conclusion}

In this paper, the syntactic distribution of the negative morpheme /sa/ has been explored within various types of predicates such as copulative verbs, non-copulative verbs and deficient verbs as well as its appearance with aspectual morphemes. It has been observed that the negative morpheme /sa/ is unevenly distributed in various types of Sesotho sentences, moods and tenses.

- With regard to non-copulative verbs, the negative morpheme [sa] appears in tensed subordinated clauses within the relative and participial moods.

- With regard to copulative verbs, it only appears with the copulative verb [ba] in both the relative and the participial moods with all tenses.

- In the case of deficient verbs, its distribution is very limited. It is replaced by the deficient verb [ka] in the negative of the potential mood and does not appear with the morpheme [eso] at all. It has also been observed that the deficient verb [eso] can serve as the negative morpheme where the negative morpheme [sa] cannot be employed.

- With regard to aspectual morphemes, the negative morpheme [sa] cannot appear with the progressive aspect morpheme [sa], but can only appear as the complement of the deficient verb [sa]. It is also not allowed to appear with the temporal aspect morpheme [tswa].

Morphologically, this morpheme appears as a circumfix with the negative suffix [-e]:

$$
\begin{gathered}
\text { (34) a. Ke sa sebets-e } \\
\text { I not working } \\
\text { 'I was not working' }
\end{gathered}
$$

It has also been observed that the deficient verb [ka] has an influence on Sesotho negative morphemes, in this case the negative morpheme /sa/. In perfect compound tense, the deficient verb [ka] replaces the deficient verb [ile] where the negative morpheme /sa/ is employed:

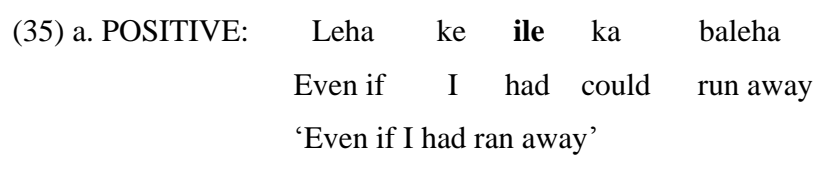




\title{
Elias Nyefolo Malete
}

\author{
b. NEGATIVE: Leha ke sa ka ka baleha \\ Even if I not could could run away \\ 'Even if I had not ran away'
}

Finally, the infinitive morpheme [ho] has a strong influence on the negative morpheme [sa] in the future tense, where the infinitive coalesces with the future tense morpheme [tla] to form [tlo]. The same thing applies to the motion verb [ya], which becomes [yo] when coalesced with the infinitive. The relative suffix is employed to force acceptability of such construction. The table below illustrates:

Table 1. Negative morpheme [sa]

\begin{tabular}{|c|c|c|c|}
\hline Category & Infinitive [ho] & Coalesced form & Negatives \\
\hline ile + & ho & ilo - ng & ${ }^{*} \mathrm{Ba}$ - sa - ilong ho bua \\
\hline tlile + & ho & tlilo-ng & ${ }^{*} \mathrm{Ba}$ - sa - tlilong ho bua \\
\hline tle + & ho & tlo / tlo - ng & $\begin{array}{l}\mathrm{Ba} \text { - sa - tlong ho bua } \\
\mathrm{Ba} \text { - sa tlo - bua / ho bua }\end{array}$ \\
\hline $\mathrm{ya}+$ & ho & yo - ng & $\mathrm{Ba}$ - sa - yong ho di ja \\
\hline
\end{tabular}

\section{References}

Beard, R. 1995. Lexeme-Morpheme Base Morphology. [M] New York Press.

Blake, E and Moorhead. 1993. Introduction to English Language. [M] Basingstoke: Macmillan.

Chapole, S. 1992. The tense system of Southern Sotho. [A] In D.F. Gowlett (ed.): African Linguistic contributions. [C] Via Africa. Pretoria

Doke, C.M and S.M Mofokemg. 1985. Textbook of Southern Sotho Grammar. [M] Maskew Miller Longman. Cape Town

Du Plessis, J. A. and Visser, M. W. 1992. Xhosa Syntax. [M] Pretoria : Via Afrika.

Du Plessis, J. A. and Visser, M.W. 1995. Sesotho Syntax. [J] Stellenbosch Communications in African Languages. No.6. University of Stellenbosch.

Guldemann, T. 1999. Bantu Historical Linguistics: Theoretical and Empirical Perspectives. [A] In Hombert,J and L.M. Hyman (eds.): The Genesis of Verbal Negation in Bantu and its Dependency on Functional Features of Clause Type. [C] CSLI Publications. U.S.

Guma, S.M. 1971. An Outline Structure of Southern Sotho. [M] Shuter and Shooter. Pietermaritzburg. S.A.

Haegeman, L.M.V. 1995. The Syntax of Negation. [M] Cambridge University Press.

Haegeman, L. 1997. Elements of Grammar. [A] In Haegeman (ed.): Elements of Grammar: Handbook in Generative Syntax. [C] Kluwer Academic Publishers. Netherlands.

Klima, J. 1964. Negation in English. [A] In J. Fodor and Katz (eds.): The Structure of Language. [C] New Jersey: Prentice - Hall.

Malete, E.N. 1996. Adjecency in Sesotho. [D] Unpublished M.A. Dissertation. University of Stellenbosch.

Sithole, N.V. 2003. Event Structure in Zulu. [D] Unpublished D.Litt.Dissertation. University of Stellenbosch

Thrainsson, H and W. Abraham et al. 1996. Minimal Ideas. [M] John Benjamins. Harvard.

Zanuttini, R. 1997. Negation and Clausal Structure: A Comparative Study of Romance Languages. [M] Oxford University Press. Oxford. 